\title{
Occupational health in oral radiologists: A review
}

\author{
Flor Euclibia Londoño-Candonaza ${ }^{1,2, A-F}$, Gustavo Adolfo Fiori-Chincaro, ${ }^{1,2, A-F}$, Ana María Agudelo-Botero ${ }^{1,2, A, C-F}$, \\ Jhoana Llaguno-Rubio ${ }^{1,2, A-F}$, Luis Ernesto Arriola-Guillén ${ }^{1,2, A-F}$ \\ ${ }^{1}$ Division of Orthodontics, School of Dentistry, Scientific University of the South, Lima, Peru \\ 2 Division of Oral and Maxillofacial Radiology, School of Dentistry, Scientific University of the South, Lima, Peru \\ A - research concept and design; $\mathrm{B}$ - collection and/or assembly of data; $\mathrm{C}$ - data analysis and interpretation; \\ $D$ - writing the article; $E$ - critical revision of the article; $F$ - final approval of the article
}

Address for correspondence

Luis Ernesto Arriola-Guillén

E-mail: luchoarriola@gmail.com

Funding sources

None declared

Conflict of interest

None declared

Received on January 26, 2021

Reviewed on March 6, 2021

Accepted on March 23, 2021

Published online on September 30, 2021

Cite as

Londoño-Candonaza FE, Fiori-Chincaro GA, Agudelo-Botero AM,

Llaguno-Rubio J, Arriola-Guillén LE. Occupational health in oral

radiologists: A review. Dent Med Probl. 2021;58(3):405-410.

doi:10.17219/dmp/134789

DOI

$10.17219 / \mathrm{dmp} / 134789$

Copyright

(C) 2021 by Wroclaw Medical University

This is an article distributed under the terms of the

Creative Commons Attribution 3.0 Unported License (CC BY 3.0)

(https://creativecommons.org/licenses/by/3.0/).

\begin{abstract}
Work is a fundamental axis for the development of societies and human well-being, but if a person cannot adapt to their work area and work environment, the individual may be affected by occupational or coexisting illnesses that get exacerbated when working.

A scientific search was conducted in the main health databases - MEDLINE (via PubMed), Web of Science, SciELO, Scopus, Google Scholar, and Dialnet - using the keywords "occupational health", "occupational diseases", "occupational accidents" AND "oral radiology" OR "oral radiologists". Systematic reviews as well as observational, cross-sectional and longitudinal studies were included. Case reports, letters to the editor, editorials, and opinion articles were excluded. In total, 496 articles were recovered, and only 51 fulfilled the selection criteria. Signs and symptoms that affect oral radiologists include back pain, shoulder pain, wrist pain, tenosynovitis, computer vision syndrome (CVS), stress, depression, and burnout syndrome. Preventive occupational health $(\mathrm{OH})$ measures are proposed to help eliminate or alleviate the symptoms associated with non-ergonomic habits at work. Oral radiologists are exposed to several risks and occupational diseases inherent and/or related to their work. By implementing simple habits and ergonomic advice, well-documented in the literature, these risks can be avoided.

This review aimed to provide scientific information on the current concepts of $\mathrm{OH}$ in oral radiologists in order to help prevent occupational diseases and occupational accidents, and guarantee safe professional practice.
\end{abstract}

Keywords: occupational health, ergonomics, radiology, dental staff 


\section{Introduction}

Work plays an especially important role in the development of human societies. As knowledge and technology advance, the forms, modes and environments of work also advance. ${ }^{1}$ It has been shown that the health of workers is conditioned by different social and individual factors as well as by access to health services, and the forms, modes and environments of work. ${ }^{2,3}$

Occupational health $(\mathrm{OH})$ has been defined by the Pan American Health Organization (PAHO) as the promotion and maintenance of the highest degree of physical, mental and social well-being of workers in all occupations by preventing deviations from health, controlling risks, and adapting work to people and people to their work positions. ${ }^{3-5}$ Since $\mathrm{OH}$ is based on the law, each country has its decrees, laws and regulations, created according to the guidelines of the United Nations (UN), the European Union (EU) and the Organization of American States (OAS), which are major international mainstays for countries. ${ }^{4,6,7}$

The International Labor Organization (ILO) has classified occupational diseases into the following groups: those caused by chemical, physical or biological agents; infectious or parasitic diseases; respiratory diseases; skin diseases; musculoskeletal disorders; mental and behavioral disorders; occupational cancer; and diseases caused by other substances and agents, not included in any of the abovementioned sections. There are also other diseases, not included on this list, that may be related to work activities. ${ }^{5,7-9}$

Oral radiology is a discipline that involves the diagnosis of the diseases and disorders of the mouth, face and jaws with the use of X-rays and other types of radiological techniques. Apart from diagnosing a disease, radiological examinations enable the development of treatment plans and the monitoring of the evolution of lesions and the disease over time. ${ }^{6,10-14}$ This profession presents many inherent risks related to the occurrence of diseases and work-associated accidents, which may imply immediate or long-term problems. Moreover, an important aspect to consider is that health professionals, including oral radiologists, live in a competitive environment that is highly demanding and seeks perfection in their daily work; this leads to high levels of emotional stress. ${ }^{15-18}$ In addition, the impact of the coronavirus disease 2019 (COVID-19) pandemic on mental health, and consequently on the professional practice of the whole medical staff, must be taken into consideration. ${ }^{19-21}$

This review evaluates the discomfort, illnesses and occupational problems derived from the practice of oral radiology, and proposes some ergonomic recommendations. ${ }^{1,3,7,8,14}$ Further, the purpose of this review was to provide scientific information on the current concepts of $\mathrm{OH}$ in oral radiologists in order to help prevent occupational diseases and occupational accidents, and guarantee safe professional practice.

\section{Methodology}

A literature search was carried out using the main sources of scientific information, such as MEDLINE (via PubMed), Web of Science, SciELO, Scopus, Google Scholar, and Dialnet, and search terms with a date limitation of the last 10 years to include information regarding $\mathrm{OH}$ and oral radiology. The keywords used were "occupational health", "occupational diseases", "occupational accidents", "ergonomic", "oral radiology", and "oral radiologists". Systematic reviews as well as observational, cross-sectional and longitudinal studies were included. Case reports, letters to the editor, editorials, and opinion articles were excluded. Thus, 496 articles were recovered, of which only 51 fulfilled the selection criteria. These studies were included to evaluate the development of theoretical topics. The bibliographic search was carried out until December 5, 2020 (Fig. 1).

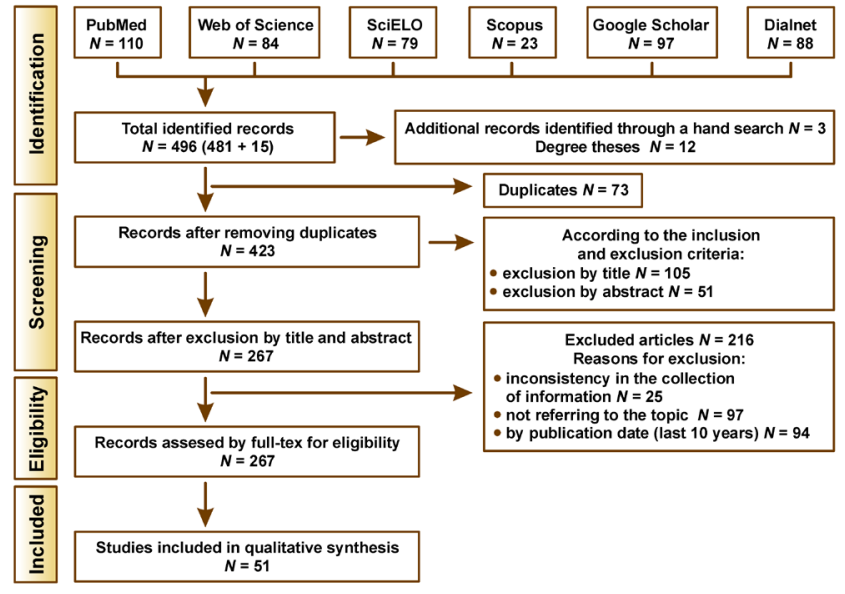

Fig. 1. Flow chart for collecting information

\section{General aspects of occupational health}

In recent decades, globalization, technology, the diversification of societies, demographic changes, and the overcrowding of cities have exerted a strong impact on the workplace, leading to the concept of work ethics. This concept is important, since it seeks to balance the risks and benefits between the interested or contracting parties, which, in this case, involve employees and employers. $^{7}$

Work is linked with health and can affect not only physical health, but also mental health due to the transfer of workload to home or other personal spheres. Epidemiological studies have shown that the morbidity and mortality of a population are closely related to labor demands. Occupational accidents due to inadequate working conditions, or worker or employer negligence, can not only have strong repercussions on health, but can also end life. ${ }^{8,9}$ 
Access to health services adds to the quality of life of populations, families and workers. A study carried out in 17 countries of EU evaluated the health systems of each country and reported that while worker healthcare was mandatory, annual controls to assess the work capacity of workers, and human, institutional and infrastructure resources were insufficient. ${ }^{10,11}$

\section{Occupational diseases in oral radiology}

Work-related musculoskeletal symptoms refer to muscular, nerve, cartilaginous, bone, tendon, vascular, or joint-related discomfort in various parts of the body and the human support system that are mainly attributable to the work environment and increasingly worsen over time. Over time, musculoskeletal complaints can become longterm degenerative disorders that decrease productivity at work. $^{12}$

In the study by Al Shammari et al, the most prevalent discomfort reported by radiologists was lumbar pain, pain in the upper extremities and the carpal tunnel, and tenosynovitis. ${ }^{13}$ Other studies described pain in the lower back and the spine as well as the neck, as repetitive stress injuries. ${ }^{14,22}$ According to various studies, radiologists most frequently report pain or discomfort at least once a week in the neck (66\%), the lower back (61\%), the upper back (43\%), the right shoulder (36\%), and the right wrist (33\%). ${ }^{13,23}$

Stress is becoming more and more common in the workplace. It has been reported that $55 \%$ of radiologists experience symptoms related to stress and exhaustion. Stress often results in physical and emotional consequences, including cardiovascular problems, the lack of sleep, and in extreme cases, severe psychological disorders. The associated risk factors for stress are feeling undervalued, feeling belittled, the inability to achieve goals, experiencing barriers that prevent the person from performing their work and achieving personal development, working conditions, unfair work rules, and loneliness, which combined, can generate synergy. ${ }^{24,25}$

Clinical depression can also affect radiologists, with the most common diagnostic criteria being a depressed mood most of the time, the loss of pleasure, the loss of interest in most of the daily activities, slowing down in carrying out daily activities, a decreased appetite, an unjustified weight loss, permanent insomnia or hypersomnia, restlessness, fatigue and tiredness almost every day and all day, a decreased ability to think, concentrate or make decisions, feelings of guilt and low self-worth, and thoughts of death (the fear of death or suicidal thoughts). A professional is defined as having depression with the presentation of 5 or more of these criteria for a period of 2 or more weeks. ${ }^{26,27}$

Burnout syndrome involves chronic work stress that affects a person in all facets of their life, both in the work environment and outside. Some of the consequences of this syndrome are low self-esteem, low energy, the inability to fall asleep, permanent fatigue, weakness, a feeling of frustration, negative attitudes, increased irritability, the degeneration of social relationships, the loss of motivation with regard to life affairs, and depression. ${ }^{28}$ This syndrome has 3 components: emotional exhaustion, a feeling of frustration, and a negative attitude toward oneself and others. ${ }^{29}$ In South America, the stress levels associated with burnout syndrome are low among radiologists ${ }^{30,31}$; however, high levels of burnout have been reported in Canada, both in apprentices and professionals. ${ }^{32,33}$ On the other hand, in India, 54\% of radiologists report repetitive stress injuries, $52 \%$ of which are accompanied by pain in the neck. ${ }^{34}$

Computer vision syndrome (CVS) has been defined by the American Optometric Association (AOA) as a set of ocular and visual problems related to activities involving near vision, and is experienced while using computers. ${ }^{35}$ The manifested symptoms are headache, difficulty in focusing, dry eyes, red eyes, irritated eyes, double vision, and blurred vision, all of which are strongly related to the number of hours in front of a screen. Among Canadian radiologists, the prevalence of CVS is $36 \% .^{36-38}$

Metabolic syndrome describes several conditions that include hyperglycemia, high triglyceride and cholesterol levels, obesity, and hypertension. These parameters are found to be higher in professionals with a higher degree of work stress. It has been described that $7.1 \%$ of radiologists have metabolic syndrome, presenting 3 or more simultaneous pathological metabolic abnormalities. ${ }^{39}$ More scientific evidence on metabolic syndrome among radiologists is required.

Despite the advent of digital radiology, the use of analog radiology is still common today in many parts of the world. Therefore, the working conditions and the substances used for image processing can affect the health of radiologists. Some of the symptoms described include headaches, a sore throat, a shortness of breath, skin rash, a bad taste in the mouth (chemical taste), a runny nose, itchy eyes, nausea, asthma, fatigue, watery eyes, a persistently stuffy nose, a persistently itchy nose, and sneezing, which are collectively known as "darkroom disease".

Additionally, an important aspect to consider is that health professionals, including oral radiologists, have been negatively impacted by the COVID-19 pandemic. The disease has had a significant effect on mental health of the whole medical staff, and consequently on professional practice. ${ }^{19-21}$ Therefore, a good, healthy and comfortable work environment is required.

\section{Ergonomics in dental radiology}

The International Ergonomics Association (IEA) defines ergonomics as the scientific discipline of studying the individuals' relationships, interactions and adapta- 
tions with/to the work environment and each of the elements that compose it, in order to guarantee human well-being and the productivity of the system, to achieve maximum efficiency in terms of the use of movements, space and time, to minimize physical and mental stress, and to prevent occupational diseases, which can be very difficult to treat once they appear. ${ }^{41}$

In the work setting, equipment must be close by, and must be silent and acoustic. ${ }^{42}$ Good lighting, including that of the ambient light sources, screens and monitors, is important. A balance between screen lighting and ambient lighting ensures that the radiologist can observe small details. More studies are required to determine the standard maximum luminance of radiological equipment. $^{35,43,44}$

To avoid the symptoms associated with CVS, it is recommended to blink continuously, making this exercise a conscious act. A short break should be made by observing distant objects for at least 5 minutes every 2 hours. Computer screens should be placed below the eye level, i.e., the top edge of the monitor should be below the eye level and further from the eyes than the bottom edge so that there is a downward angle of $14^{\circ}$. The optimum distance from the monitor to the eyes should be at arm's length, or 76-101.5 cm away with a 5-millimeter font size. $^{45-47}$

Radiologists should perform a simple stretching exercise every hour of work. ${ }^{48,49}$ The chairs utilized by radiologists must be adjustable. Whilst sitting, the radiologist's feet must not dangle, but rather must be supported on the ground forming an angle of $90-105^{\circ}$ between the calves and the thighs. The use of arm supports relieves the effort of the muscles of the back. Curved chairs cause upper body ailments, whereas flat chairs cause lower body ailments. ${ }^{50,51}$ An optimal working environment has a temperature of $20-25^{\circ} \mathrm{C}$ with $40-60 \%$ humidity. ${ }^{43,52,53}$ Noise should be minimized as much as possible; however, the maximum noise threshold that should be allowed at the workstation is $58 \mathrm{~dB} \cdot{ }^{54-56}$ When using the mouse, the hand and the wrist should be positioned possibly parallel to the desk. A mouse with a slight increase in height in the most anterior part is recommended (Table 1). ${ }^{57-60}$

Table 1. Occupational diseases and their origin, and recommendations related to the work activities of oral and maxillofacial radiologists

\begin{tabular}{|c|c|c|}
\hline Occupational discomfort & Causes & Ergonomic recommendations \\
\hline $\begin{array}{l}\text { Lower back } \\
\text { and upper limb pain }\end{array}$ & $\begin{array}{l}\text { sustained and bad postures, uncomfortable } \\
\text { chairs, desks of insufficient or excessive } \\
\text { height, limited space }\end{array}$ & $\begin{array}{l}\text { - a simple stretching exercise and an active break every hour of work } \\
\text { - furniture adjustable to the figure and height of the person } \\
\text { - using a chair that can be adjusted to the needs of the person sitting on it and can } \\
\text { provide good lumbar support, without causing pressure on the thighs and without } \\
\text { the feet hanging; the feet must be supported on the ground at an angle of } 90-105^{\circ}\end{array}$ \\
\hline $\begin{array}{l}\text { Carpal tunnel } \\
\text { and tenosynovitis }\end{array}$ & $\begin{array}{l}\text { repetitive movements with the hands, } \\
\text { sustained and awkward postures while } \\
\text { using the mouse and the keyboard, } \\
\text { transcription of reports in a bad posture }\end{array}$ & $\begin{array}{l}\text { - the mouse and the keyboard should be arranged in such a way so that to } \\
\text { minimize the deflection, extension and flexion of the wrist } \\
\text { - the mouse should be grasped with the dominant hand and the wrist should be } \\
\text { positioned possibly parallel to the desk, a mouse with a slight increase in height in the } \\
\text { most anterior part is recommended as well as using gel support pads for the wrists } \\
\text { - using a DictaphoneTM }\end{array}$ \\
\hline Neck pain & $\begin{array}{l}\text { sustained head postures with excessive up } \\
\text { or down head movements }\end{array}$ & $\begin{array}{l}\text { - placing the computer screen below the eye level so that to ensure is } \\
\text { a 14-degree downward gaze }\end{array}$ \\
\hline Burnout syndrome & $\begin{array}{l}\text { extended working hours, excessive } \\
\text { workload, difficult employment } \\
\text { relationships, lack of resources to perform } \\
\text { duties properly, neglect of facets of life } \\
\text { other than work }\end{array}$ & $\begin{array}{l}\text { - maintaining a balance between work and family life } \\
\text { - coping with dictatorial hierarchies } \\
\text { - avoiding severe self-criticism } \\
\text { - providing sufficient salary rewarding, having a number of employees according to } \\
\text { the work volume, allowing spaces for the members of the work team to integrate, } \\
\text { respecting nighttime hours and weekends, not interrupting with calls, avoiding } \\
\text { tasks to be done at home, outside the workplace and working hours }\end{array}$ \\
\hline Clinical depression & $\begin{array}{l}\text { endogenous origin or biological, genetically } \\
\text { determined predisposition, enhanced by } \\
\text { environmental factors or reactive factors } \\
\text { that occur in the face of poor adaptation to } \\
\text { stressful environmental factors }\end{array}$ & $\begin{array}{l}\text { - occupational medical services regarding mental health focused on medical } \\
\text { professionals, including radiologists } \\
\text { - controlling any physical illness }\end{array}$ \\
\hline CVS & $\begin{array}{l}\text { activities that stress near vision and are } \\
\text { related to using computers }\end{array}$ & $\begin{array}{l}\text { - adequate ambient lighting } \\
\text { - full blink, 5-minute breaks every } 2 \mathrm{~h} \text {, yearly eye exams } \\
\text { - using anti-glare filters on monitor screens } \\
\text { - use software that reduces blue light } \\
\text { - temperature of } 20-25^{\circ} \mathrm{C} \text { with } 40-60 \% \text { humidity }\end{array}$ \\
\hline Suicidal thoughts & $\begin{array}{c}\text { depression, anxiety, bipolar disorder, } \\
\text { psychoactive substance abuse, alcoholism, } \\
\text { loneliness }\end{array}$ & $\begin{array}{l}\text { - OH services involving the treatment of depression, bipolar disorder, } \\
\text { psychoactive substance abuse, alcoholism, self-medication, and feel-good } \\
\text { medication }\end{array}$ \\
\hline Metabolic syndrome & $\begin{array}{l}\text { high degree of work stress, sedentary } \\
\text { lifestyle, unhealthy lifestyle }\end{array}$ & $\begin{array}{l}\text { - promoting a healthy lifestyle } \\
\text { - physical activity } \\
\text { - regular medical exams }\end{array}$ \\
\hline
\end{tabular}

CVS - computer vision syndrome; $\mathrm{OH}$ - occupational health. 
Occupational medical services for medical professionals, including radiologists, should focus on mental health for the early detection of depression, stress, chronic exhaustion, bipolar disorder, psychoactive substance abuse, alcoholism, self-medication to feel good as well as suicide risk factors.

Situations related to lawsuits or possible lawsuits should be managed. Long work hours should be avoided and sufficient sleep is essential. Efforts must be made to maintain a balance between work and family life. A healthy lifestyle must also be promoted by getting physical activity and controlling any physical illness. Work hierarchies that do not tolerate mistakes must be overcome, and also severe self-criticism should be avoided. From an employer's point of view, sufficient salary rewarding should be given according to the context, region, functions, and professional title. Additionally, the number of employees should be in accordance with the work volume. Free-time spaces should be available for the members of the work team to integrate. Nighttime and weekend hours must be respected, and interruptions with calls or tasks outside the workplace and working hours should not be made. In addition, tasks that are needed to be done at home must be avoided. Lastly, it is recommended to spend time outdoors to allow contact with the sun. Exposure to sunlight stimulates the secretion of the hormones serotonin and melatonin, which are related to feelings of well-being and happiness, and sleep.

\section{Conclusions}

Oral radiologists are exposed to several risks and occupational diseases inherent and/or related to the work. However, these risks can be avoided by the implementation of the well-documented habits and ergonomic advice that improve a person's overall quality of life.

\section{ORCID iDs}

Flor Euclibia Londoño-Candonaza (1)

https://orcid.org/0000-0002-5665-5802

Gustavo Adolfo Fiori-Chincaro (1) https://orcid.org/0000-0001-9273-8587 Ana María Agudelo-Botero (1) https://orcid.org/0000-0002-0658-8517 Jhoana Llaguno-Rubio (1) https://orcid.org/0000-0002-0223-608X Luis Ernesto Arriola-Guillén (10 https://orcid.org/0000-0003-0010-5948

\section{References}

1. Sandoval-Reyes J, Acosta-Prado JC, Sanchís-Pedregosa C. Relationship amongst technology use, work overload, and psychological detachment from work. Int $J$ Environ Res Public Health. 2019;16(23):4602. doi:10.3390/ijerph16234602

2. Burton WN, Chen CY, Li X, Schultz AB. The association of employee engagement at work with health risks and presenteeism. J Occup EnvironMed.2017;59(10):988-992. doi:10.1097/JOM.0000000000001108

3. Whysall Z, Bowden J, Hewitt M. Sickness presenteeism: Measurement and management challenges. Ergonomics. 2018;61(3):341-354. doi:10.1080/00140139.2017.1365949

4. Arenas Massa A, Riveros Ferrada C. Ethical and legal aspects of occupational health [in Spanish]. Pers Bioét. 2017;21(1):62-77.

5. Lezaun M. Legislation on professional respiratory diseases [in Spanish]. An Sist Sanit Navar. 2005;28(Suppl 1):123-134.
6. Paz Gallardo C, Celis Contreras C, Schilling Quezada A, Schilling Lara J, Hidalgo Rivas A. Contribution of oral and maxillofacial radiology to the clinical diagnosis [in Spanish]. Av Odontoestomatol. 2019;35(2):73-82. doi:10.4321/s0213-12852019000200004

7. Iavicoli S, Valenti A, Gagliardi D, Rantanen J. Ethics and occupational health in the contemporary world of work. Int J Environ Res Public Health. 2018;15(8):1713. doi:10.3390/ijerph15081713

8. Guillén Subiran C. The challenge of managing occupational diseases: Solvitas perambulum [in Spanish]. Med Segur Trab. 2014;60(Suppl 1):144-156. http://scielo.isciii.es/scielo. php?script=sci_arttext\&pid=S0465-546X2014000500021\&lng=es. Accessed December 4, 2020.

9. Palacios Nava ME, Moreno Sánchez AR, Paz Román MDP, García García JJ, Nava Hernández R. Situation of occupational and environmental health in Mexico. Ann Glob Health. 2018;84(3):348-359. doi:10.29024/aogh.2317

10. Sakowski P, Marcinkiewicz A. Health promotion and prevention in occupational health systems in Europe. Int J Occup Med Environ Health. 2019;32(3):353-361. doi:10.13075/ijomeh.1896.01384

11. Rantanen J, Lehtinen S, Valenti A, lavicoli S. A global survey on occupational health services in selected international commission on occupational health (ICOH) member countries. BMC Public Health. 2017;17(1):787. doi:10.1186/s12889-017-4800-z

12. Sze G, Bluth El, Bender CE, Parikh JR. Work-related injuries of radiologists and possible ergonomic solutions: Recommendations from the ACR Commission on Human Resources. J Am Coll Radiol. 2017;14(10):1353-1358. doi:10.1016/j.jacr.2017.06.021

13. Al Shammari M, Hassan A, Al Dandan O, Al Gadeeb M, Bubshait D. Musculoskeletal symptoms among radiologists in Saudi Arabia: A multi-center cross-sectional study. BMC Musculoskelet Disord. 2019;20:541. doi:10.1186/s12891-019-2933-1

14. Creze $M$, Bedretdinova $D$, Soubeyrand $M$, et al. Posture-related stiffness mapping of paraspinal muscles. J Anat. 2019;234(6):787-799. doi:10.1111/joa.12978

15. Viegas S, Jeddi MZ, Hopf NB, et al. Biomonitoring as an underused exposure assessment tool in occupational safety and health context - challenges and way forward. Int J Environ Res Public Health. 2020;17(16):5884. doi:10.3390/ijerph17165884

16. Zhu B, Fan H, Xie B, Su R, Zhou C, He J. Mapping the scientific research on healthcare workers' occupational health: A bibliometric and social network analysis. Int J Environ Res Public Health. 2020;17(8):2625. doi:10.3390/ijerph17082625

17. Vargas SC, de Oliveira CF, Pollo Renner JD, Franz Krug SB, Possuelo L. Prevalence of occupational infectious diseases among primary oral health care teams and prevention measures. Rev Bras Med Trab. 2020;18(2):149-157. doi:10.47626/1679-4435-2020-546

18. Shi $Y$, Xue $H, M a Y$, et al. Prevalence of occupational exposure and its influence on job satisfaction among Chinese healthcare workers: A large-sample, cross-sectional study. BMJ Open. 2020;10(4):e031953. doi:10.1136/bmjopen-2019-031953

19. Koh D, Goh HP. Occupational health responses to COVID-19: What lessons can we learn from SARS? J Occup Health. 2020;62(1):e12128. doi:10.1002/1348-9585.12128

20. Giorgi G, Lecca LI, Alessio F, et al. COVID-19-related mental health effects in the workplace: A narrative review. Int J Environ Res Public Health. 2020;17(21):7857. doi:10.3390/ijerph17217857

21. Celik V, Ozkars MY. An overlooked risk for healthcare workers amid COVID-19: Occupational hand eczema. North Clin Istanb. 2020;7(6):527-533. doi:10.14744/nci.2020.45722

22. Parikh JR, Bender C, Bluth E. Musculoskeletal injuries affecting radiologists according to the 2017 ACR Human Resources Commission workforce survey. J Am Coll Radiol. 2018;15(5):803-808. doi:10.1016/j.jacr.2018.01.033

23. Seidel RL, Krupinski EA. The agony of it all: Musculoskeletal discomfort in the reading room. J Am Coll Radiol. 2017;14(12):1620-1625. doi:10.1016/j.jacr.2017.07.024

24. Fishman MDC, Mehta TS, Siewert B, Bender CE, Kruskal JB. The road to wellness: Engagement strategies to help radiologists achieve joy at work. Radiographics. 2018;38(6):1651-1664. doi:10.1148/rg.2018180030

25. Valtorta NK, Kanaan M, Gilbody S, Ronzi S, Hanratty B. Loneliness and social isolation as risk factors for coronary heart disease and stroke: Systematic review and meta-analysis of longitudinal observational studies. Heart. 2016;102(13):1009-1016. doi:10.1136/heartjnl-2015-308790 
26. Bender CE, Parikh JR, Arleo EK, Bluth E. The radiologist and depression. J Am Coll Radiol. 2016;13(7):863-867. doi:10.1016/j.jacr.2016.03.014

27. Bianchi R, Schonfeld IS, Laurent E. Burnout-depression overlap: A review. Clin PsycholRev. 2015;36:28-41.doi:10.1016/j.cpr.2015.01.004

28. Preciado Serrano MdL, Pozos-Radillo E, Colunga-Rodríguez C, Vázquez-Goñi JM, Ávalos-Latorre ML. Relationship between psychosocial factors, work emotional exhaustion and burnout in Mexican dentists [in Spanish]. Univ Psychol. 2017;16(2):1-11. doi:10.11144/Javeriana.upsy16-2.refp

29. Harolds JA, Parikh JR, Bluth El, Dutton SC, Recht MP. Burnout of radiologists: Frequency, risk factors, and remedies: $A$ report of the ACR Commission on Human Resources. J Am Coll Radiol. 2016;13(4):411-416. doi:10.1016/j.jacr.2015.11.003

30. Lozano E. Level of work stress in medical technologists in radiology of the emergency service of the hospitals Edgardo Rebagliati Martins, Alberto Sabogal Sologuren and Guillermo Almenara Irigoyen, Lima - Peru, May-August 2016 [in Spanish] (thesis for the Degree of Bachelor of Medical Technology in the area of Radiology). Faculty of Medicine, Universidad Nacional Mayor de San Marcos (UNMSM), Lima, Peru. 2017.

31. Cubas A. Radiology student burnout at the Professional School of Medical Technology at Universidad Nacional Mayor de San Marcos, 2017 [in Spanish] (thesis for the Degree of Bachelor of Medical Technology in the area of Radiology). Faculty of Medicine, Universidad Nacional Mayor de San Marcos (UNMSM), Lima, Peru. 2018. https:// cybertesis.unmsm.edu.pe/bitstream/handle/20.500.12672/7841/ Cubas_la.pdf?sequence=1\&isAllowed=y. Accessed December 4, 2020.

32. Zha N, Patlas MN, Neuheimer N, Duszak R, Jr. Prevalence of burnout among Canadian radiologists and radiology trainees. Can Assoc Radiol J. 2018;69(4):367-372. doi:10.1016/j.carj.2018.05.005

33. Ferguson C, Low G, Shiau G. Burnout in Canadian radiology residency: A national assessment of prevalence and underlying contributory factors. Can Assoc Radiol J. 2020;71(1):40-47. doi:10.1177/0846537119885672

34. Kawthalkar AS, Sequeira RA, Arya S, Baheti AD. Non-radiation occupational hazards and health issues faced by radiologists - a cross-sectional study of Indian radiologists. Indian J Radiol Imaging. 2019;29(1):61-66. doi:10.4103/ijri.IJRI_403_18

35. Chawla A, Lim TC, Shikhare SN. Computer vision syndrome: Darkness under the shadow of light. Can Assoc Radiol J. 2019;70(1):5-9. doi:10.1016/j.carj.2018.10.005

36. Teo C, Giffard P, Johnston V, Treleaven J. Computer vision symptoms in people with and without neck pain. Appl Ergon. 2019;80:50-56. doi:10.1016/j.apergo.2019.04.010

37. Atwal SS, Prasad A, Deepak D, Agarwal K. Health issues among radiologists: Toll they pay to their profession. J Clin Diagn Res. 2017;11(4):TM01-TM02. doi:10.7860/JCDR/2017/17023.9537

38. Ranasinghe $P$, Wathurapatha WS, Perera YS, et al. Computer vision syndrome among computer office workers in a developing country: An evaluation of prevalence and risk factors. BMC Res Notes. 2016;9:150. doi:10.1186/s13104-016-1962-1

39. Magnavita N, Fileni A. Work stress and metabolic syndrome in radiologists: First evidence. Radiol Med. 2013;119(2):142-148. doi:10.1007/s11547-013-0329-0

40. Chingarande $G$, Bungu $T$, Mukwasi $C$, et al. The prevalence and severity of the symptoms of darkroom disease among darkroom technicians in Harare, Zimbabwe. World J Medical Sci. 2013;8(2):113-117. doi:10.5829/idosi.wjms.2013.8.2.7319

41. Mulimani P, Hoe VC, Hayes MJ, Idiculla JJ, Abas AB, Karanth L. Ergonomic interventions for preventing musculoskeletal disorders in dental care practitioners. Cochrane Database Syst Rev. 2018;10(10):CD01126. doi:10.1002/14651858.CD011261.pub2

42. Ratwani RM, Wang E, Fong A. A human factors approach to understanding the types and sources of interruptions in radiology reading rooms. J Am Coll Radiol. 2016;13(9):1102-1105. doi:10.1016/j. jacr.2016.02.017

43. García-Lallana A, Viteri-Ramírez G, Saiz Mendiguren R, Broncano J, Dámaso Aqueretta J. Ergonomics of the workplace in radiology [in Spanish]. Radiology. 2011;53(6):507-515. doi:10.1016/j.rx.2011.06.007

44. Kallio-Pulkinnen S, Huumonen S, Haapea M, et al. Effect of display type, DICOM calibration and room illuminance in bitewing radiographs. Dentomaxillofac Radiol. 2016;45(1):20150129. doi:10.1259/dmfr.20150129
45. Randolph SA. Computer vision syndrome. Workplace Health Saf. 2017;65(7):328. doi:10.1177/2165079917712727

46. Munshi S, Varghese A, Dhar-Munshi S. Computer vision syndrome - a common cause of unexplained visual symptoms in the modern era. Int J Clin Pract. 2017;71(7). doi:10.1111/ijcp.12962

47. Dessie A, Adane F, Nega A, Wami SD, Chercos DH. Computer vision syndrome and associated factors among computer users in Debre Tabor town, northwest Ethiopia. J Environ Public Health. 2018;2018:4107590. doi:10.1155/2018/4107590

48. Stec N, Arje D, Moody AR, Krupinski EA, Tyrrell PN. A systematic review of fatigue in radiology: Is it a problem? AJR Am J Roentgenol. 2018;210(4):799-806. doi:10.2214/AJR.17.18613

49. Taylor-Phillips S, Stinton C. Fatigue in radiology: A fertile area for future research. Br J Radiol. 2019;92(1099):20190043. doi:10.1259/bjr.20190043

50. van Niekerk SM, Louw QA, Hillier S. The effectiveness of a chair intervention in the workplace to reduce musculoskeletal symptoms. A systematic review. BMC Musculoskelet Disord. 2012;13:145. doi:10.1186 / 1471-2474-13-145

51. Curran M, O'Sullivan L, O'Sullivan P, Dankaerts W, O'Sullivan K. Does using a chair backrest or reducing seated hip flexion influence trunk muscle activity and discomfort? A systematic review. Hum Factors. 2015;57(7):1115-1148. doi:10.1177/0018720815591905

52. Wolkoff P. Indoor air humidity, air quality, and health - an overview. Int J Hyg Environ Health. 2018;221(3):376-390. doi:10.1016/j. ijheh.2018.01.015

53. Davis RE, McGregor GR, Enfield KB. Humidity: A review and primer on atmospheric moisture and human health. Environ Res. 2016;144(Pt A):106-116. doi:10.1016/j.envres.2015.10.014

54. Xyrichis A, Wynne J, Mackrill J, Rafferty M, Carlyle A. Noise pollution in hospitals. BMJ. 2018;363:k4808. doi:10.1136/bmj.k4808

55. Lusk SL, McCullagh M, Dickson VV, Xu J. Position statement: Harmful effects of environmental noise exposures. Nurs Outlook. 2016;64(4):395-396. doi:10.1016/j.outlook.2016.06.001

56. Lusk SL, McCullagh M, Dickson VV, Xu J. Reduce noise: Improve the nation's health. Nurs Outlook. 2017;65(5):652-656. doi:10.1016/j.outlook.2017.08.001

57. Odell D, Johnson P. Evaluation of flat, angled, and vertical computer mice and their effects on wrist posture, pointing performance, and preference. Work. 2015;52(2):245-253. doi:10.3233/WOR-152167

58. Kia K, Sisley J, Johnson PW, Kim JH. Differences in typing forces, muscle activity, wrist posture, typing performance, and selfreported comfort among conventional and ultra-low travel keyboards. Appl Ergon. 2019;74:10-16. doi:10.1016/j.apergo.2018.07.014

59. Bluth El, Bender CE, Parikh JR. Burnout: Redesign the work process rather than the person. J Am Coll Radiol. 2017;14(10):1375-1376. doi:10.1016/j.jacr.2017.05.004

60. Ayala-Álvarez RI, Fiori Chíncaro G. Review of the main radiation protection standards for the use of X-ray equipment in dentistry. Literature review [in Spanish]. Rev Cient Odontol (Lima). 2019;7(2):119-133. doi:10.21142/2523-2754-0702-2019-119-133 